\title{
Multiuser Interaction with Hybrid VR and AR for Cultural Heritage Objects
}

\author{
Yue Li \\ International Doctoral \\ Innovation Centre \& NVIDIA \\ Joint-Lab on Mixed Reality \\ University of Nottingham \\ Ningbo, China \\ yueli@nottingham.edu.cn
}

\author{
Eugene Ch'ng \\ NVIDIA Joint-Lab on Mixed \\ Reality \\ University of Nottingham \\ Ningbo, China \\ eugene.chng@nottingham.edu.cn
}

\author{
Shengdan Cai \\ Faculty of Humanities and Social \\ Sciences \& \& NVIDIA Joint-Lab \\ on Mixed Reality \\ University of Nottingham \\ Ningbo, China \\ shengdan.cai@nottingham.edu.cn
}

\author{
Simon See \\ NVIDIA AI Technology Centre \\ NVIDIA \\ Singapore \\ ssee@nvidia.com
}

\begin{abstract}
This research investigates the factors and ways in which users initiate conversations and engage in interactions in a hybrid virtual environment using a combination of Virtual Reality (VR) and Augmented Reality (AR) devices. The research was done in the 'spirit of the ancient Silk Road' where trade brought in exchange of ideas, cultural influence and cross-border communications. The notion of a $21^{\star}$ century Silk Road is necessarily digital, over the Internet and based around 3D cultural heritage objects. Digi-Capital's Report forecasts the revenue of $A R$ and VR to be US\$150b by 2020 . We projected that VR and AR will become pervasive, much like the Social Web and the universal ubiquity of mobile devices such as smartphones and wearables. Here, we conducted a user study exploring users' acceptance of the use of hybrid VR and AR for cultural heritage, and investigated the social nature of multiple co-located user interaction. We adapted the UTAUT questionnaire in our experiment and found that social influence has positive effects on performance expectancy and effort expectancy, which generate positive effects on user behavioural intention. This study pioneers the future design and use of hybrid VR and AR technology in cultural heritage specifically, and in other application areas generally by highlighting the significant role that social influence plays in enhancing users' behavioural intention facilitated by different immersive devices.
\end{abstract}

Keywords-virtual reality, augmented reality, hybrid $V R A R$, technology acceptance, interaction design, social interaction, cultural heritage, heritage objects

\section{INTRODUCTION}

The ancient Silk Road was a network of multiple trade routes that played a significant role in the expansion of trade and culture between the East and the West. In particular, heritage objects can encapsulate both history and the remarkable stories of the time. They were both objects of trade, of symbolic importance and of personal sentiments from which conversations occurred and money and friendships exchanged. In contemporary times the objects are preserved, distributed in museums all over the world. While a significant number of objects are not on display, those on display are not accessible, at least for people who do not have the means to travel to museums in multiple locations. The advent of digital technology and interface devices could provide not only global accessibility, but communications, narratives, and most importantly, the 'spirit of the ancient Silk Road' - social interaction and exchange of ideas, all supported by transformative digital technologies and the Social Web (Web 2.0).

Literature in museum studies has emphasised the importance of visitors' social nature and highlighted that collective activities in visitor experience do strengthen memorability, enhance engagement and contribute to the general user experience [1]. Digital technology is at a stage where highly realistic objects and environments, real-time interactivity, and multiuser virtual experience have become possible [2]. The 'in-the-wild' study suggests that the devices for Virtual Reality (VR) and Augmented Reality (AR) can be adopted for use within 3 minutes by first-time users [3]. Since VR and AR technologies are object-centric, presenting objects to users via displays, it brings into question how they would work in a hybrid environment when multiple users attempt to interact and communicate with different devices around digital objects. As far as we know, there has been no study to-date investigating technology acceptance of hybrid VR and AR devices, especially in their use for accessing cultural heritage objects. The research explores the use of hybrid VR and AR in a multiuser application and investigates users' acceptance of the technologies, proposing and testing a theoretical model incorporating social influence, performance expectancy, effort expectancy, and behavioural intention. In our work, we created a virtual environment with digitised Chinese relics with interface technologies shared between the HTC Vive and a mobile AR app. Questionnaires and interviews were carried out provide a highly objective and in-depth view of users' acceptance towards the use of VR and AR in cultural heritage with a social context and the mechanisms of multiuser interactions around artefacts. 


\section{BACKGROUND}

VR has a long history of research, beginning with its initial use within the military simulations and medical applications domain [4]. VR has since been applied to many other areas. In our article we focus on cultural heritage, an area with a large community actively adopting VR and AR as a means of access to sites, monuments and objects. Using VR, visitors can travel back in time and experience the past [2], to explore a 10,000 year old Mesolithic village [5], and see the world's oldest calendrical system at work [6]. While the aforementioned VR applications substitute the real world with completely simulated environments, AR augments supplementary information for the real world over a display. An example is a portable AR system designed to augment fragmentary aspects of a sculpture [7]. The use of VR and AR technology for cultural heritage demonstrates new ways of accessing information. We believe that they are likely to be more widely used for visitors, for more engaging learning experience and social interaction around cultural heritage objects and environments. Access to cultural heritage is now possible outside of cultural institutions, in more private spaces such as homes for example, as VR and AR devices have been made consumer level devices, available and affordable. New ways of accessing information are making it possible for museums to open up their collections, a solution for museums lacking in space and appropriate conditions for displaying collections. Many artefacts are preserved in warehouses due to their sensitivity to light and humidity. However, by digitising these objects and presenting them using interactive VR and AR technologies, the accessibility of objects for audiences becomes a possibility, since they are no longer confined to the limited physical spaces of museums [8].

While there have been various degrees of participant studies in the use of VR and AR in cultural heritage, few have considered their use within a social context, and none using hybrid devices simultaneously. Research found that for users colocated with the VR player, even though they were not immersed in a virtual environment, they would be keen to interact with HMD users [9]. We believe that AR technology fits well with this scenario when a user wants to be part of a VR experience, but does not have access to an HMD. Such an experience provides different levels of immersion and a completely different display approach, providing users of both VR and AR a unique experience. Furthermore, we see that AR supported devices such as smartphones and tablets are comparatively more affordable, as such, they will have greater accessibility and more potentials for social use. Moreover, while motion sickness in VR can be an issue, AR could mitigate it. AR enables easier access to digital objects and social interactions, while VR being fully immersive isolates users within a virtual environment. We believe that these two needs to be combined in some ways.

A hybrid VR and AR system could be used for cultural heritage as well as other domains to contribute to knowledge in the design of multiuser, multidevice environments. We felt that user acceptance of hybrid devices is initially the key to better design. Several models of technology acceptance have been developed. One is the Technology Acceptance Model (TAM)
[10]. Despite its wide use, the model is limited as it only investigates the individual use of technology and has been criticised for its lack of consideration in the social process and consequences of the technology use. This leads to the refinement and expansion of the original model. Venkatesh et al. [11] proposed the Unified Theory of Acceptance and Use of Technology (UTAUT), taking account of the social factors. Previous research has emphasised the importance of social interactions in museums as they tend to contribute to collaborative learning through discussions, debates which lead to deeper reflections on the subject [12]. These are important and should not be compromised when introducing emerging digital technologies. Carrozzino and Bergamasco summarised several examples of VR use in cultural context and noted that users rated an overall high acceptance for two immersive VR system [13]. However, they also identified the lack of interaction and limitations of supporting multiple users in immersive systems. This confirms our argument of the necessity to further investigate user acceptance of multiuser, multidevice application with VR and AR, especially the viability of hybrid systems for facilitating interaction, engagement, and communication between users in our proposed social virtual environment.

Social influence, defined as "the degree to which an individual perceives that important others believe he or she should use the new system" [11], is a significant aspect to consider when designing systems with social support. There are design principles for facilitating human-human interaction in order to satisfy their motivational requirements on social and psychological relatedness [14]. Moreover, it was suggested that a system that support social use makes users feel related and is more likely to engage users in future use [15]. Considering that our system is a multiuser, multidevice system where social interactions will occur throughout the entire experience, we hypothesise is that social influence is likely to affect users' expectancy on performance and effort. In addition, among the four key constructs identified in UTAUT, the first three were confirmed to have positive effects on behavioural intention. Therefore, we hypothesise that social influence has a positive effect on performance expectancy and effort expectancy $(\mathrm{H} 1$, $\mathrm{H} 2$ ), and they have positive effects on behavioural intention $(\mathrm{H} 3, \mathrm{H} 4)$. The research model is shown in Fig. 1.

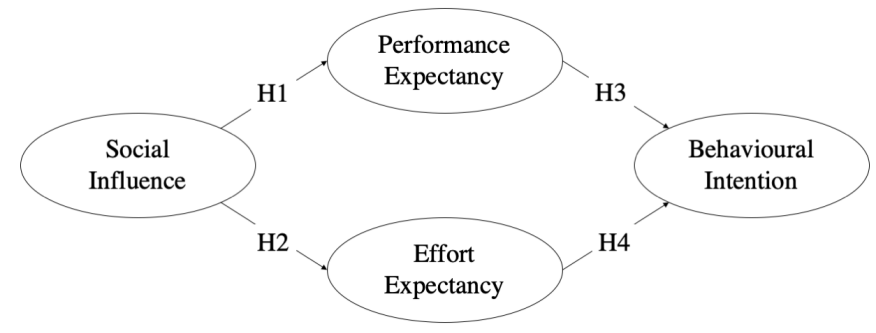

Fig. 1. Our research model, adapted from UTAUT [11]

\section{Methodology}

This section describes our virtual environment setup and the interaction design. 


\section{A. Experimental Virtual Environment}

We created a virtual environment for testing our hypotheses. Six photogrammetry reconstructed objects were arranged in a circle, placed on top of a pedestal so that each of them is equally accessible (see Fig. 2). Each object has a label containing text and images, available in both English and Chinese. The object as an interface in itself implements interaction modes, allowing it to be picked up and manipulated using tracked hand-held controllers. A Local Area Network (LAN) was established to synchronise interactions. They system allows social interaction between VR and AR users. VR users were donned with a headset with accompanying hand-held controllers; AR users viewed digital objects using a mobile device.

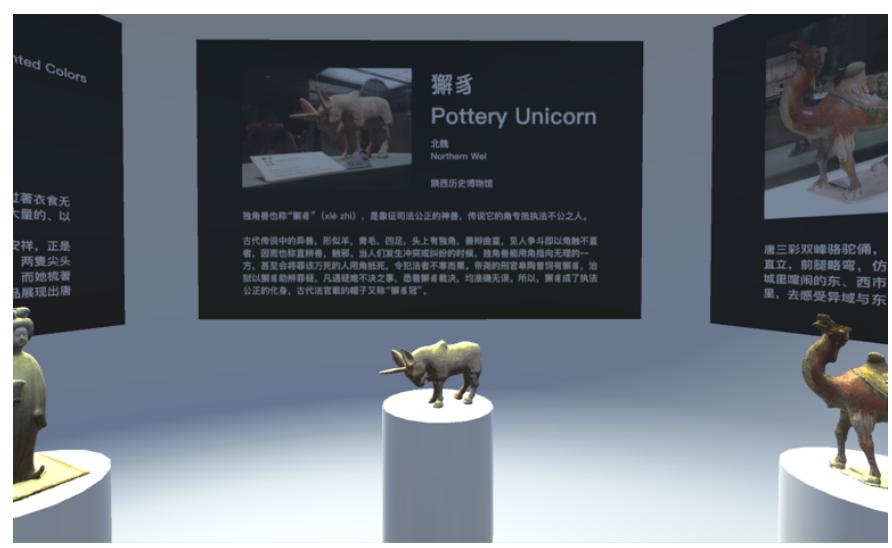

Fig. 2. Exhibition room with objects and labels

\section{1) Overview of Environment}

The virtual environment was developed in Unity (version 2018.1.0f2) built on a professional VR workstation with NVIDIA Quadro M6000 24GB graphics card and HTC Vive. Our workstation has an Intel i7 2.4GHz 12-core CPU, 64GB of RAM, and 2TB HDD. Samsung Galaxy S7 was used for accessing the digital objects and their information with AR. Vuforia AR SDK was used in the AR development [16]. The environment was kept simple but consistent, focusing only on the objects as we considered objects as the interface between VR and AR devices. Photogrammetry models were constructed, processed and imported to Unity scene for development. Detailed workflow is described in Fig. 3.

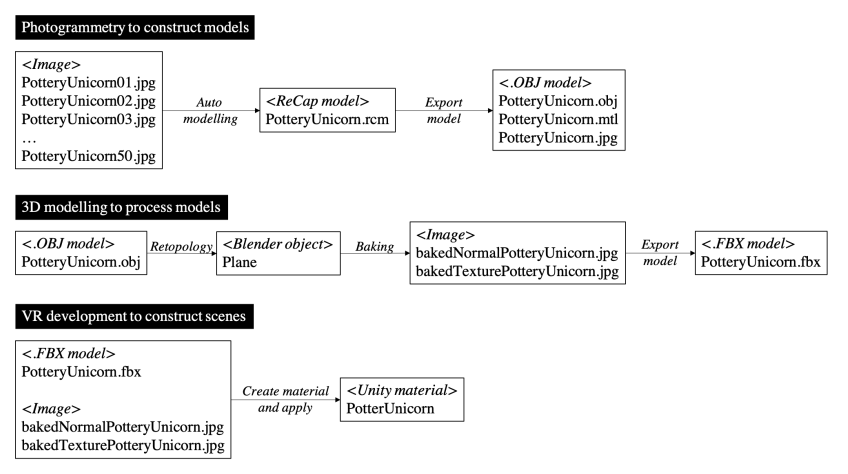

Fig. 3. Process workflow for digital cultural heritage objects, take the Pottery Unicorn for example (object \#4, see Table I.)

\section{2) Overview of Objects}

The virtual environment contained a mixed collection of artefacts from different time periods and materials. Details of the objects are shown in Table I.

TABLE I.

\begin{tabular}{|c|c|c|c|c|c|}
\hline \# & Name & Picture & Size & $\begin{array}{c}\text { Time } \\
\text { Period }\end{array}$ & Museum \\
\hline & $\begin{array}{l}\text { Bronze Music } \\
\text { Instrument }\end{array}$ & & $\begin{array}{l}\text { Height: } \\
63 \mathrm{~cm}\end{array}$ & $\begin{array}{c}\text { Western } \\
\text { Zhou }\end{array}$ & $\begin{array}{l}\text { Tianjin } \\
\text { Museum }\end{array}$ \\
\hline 2 & $\begin{array}{c}\text { The Bronze } \\
\text { Mask with } \\
\text { Protruding } \\
\text { Pupils }\end{array}$ & & $\begin{array}{l}\text { Height: } \\
66 \mathrm{~cm} \\
\text { Width: } \\
138 \mathrm{~cm}\end{array}$ & Shang & $\begin{array}{l}\text { Sanxingdui } \\
\text { Museum }\end{array}$ \\
\hline & $\begin{array}{c}\text { Pottery Figure } \\
\text { of a Standing } \\
\text { Lady }\end{array}$ & & $\begin{array}{c}\text { Height: } \\
75.5 \mathrm{~cm} \\
\text { Width: } \\
26.6 \\
\mathrm{~cm}\end{array}$ & Tang & $\begin{array}{l}\text { National } \\
\text { Palace } \\
\text { Museum, } \\
\text { Taipei }\end{array}$ \\
\hline 4 & $\begin{array}{l}\text { Xie Zhi } \\
\text { (Pottery } \\
\text { Unicorn) }\end{array}$ & & & $\begin{array}{l}\text { Northern } \\
\text { Wei }\end{array}$ & $\begin{array}{c}\text { Shaanxi } \\
\text { History } \\
\text { Museum }\end{array}$ \\
\hline 5 & $\begin{array}{c}\text { Tri-coloured } \\
\text { Camel }\end{array}$ & & $\begin{array}{l}\text { Height: } \\
87 \mathrm{~cm}\end{array}$ & Tang & $\begin{array}{l}\text { Nanjing } \\
\text { Museum }\end{array}$ \\
\hline 6 & $\begin{array}{c}\text { Figure of an } \\
\text { Assistant to } \\
\text { the Judge of } \\
\text { Hell }\end{array}$ & 8 & $\begin{array}{l}\text { Height: } \\
148 \mathrm{~cm} \\
\text { Width: } \\
36 \mathrm{~cm} \\
\text { Depth: } \\
20 \mathrm{~cm}\end{array}$ & Ming & $\begin{array}{l}\text { British } \\
\text { Museum }\end{array}$ \\
\hline
\end{tabular}

\section{3) Interaction Design}

Within the virtual environment, users interacted with virtual objects by picking up and putting down using hand-held controllers. Objects being picked up were highlighted with an outline, and were snapped to its original position on the pedestal when the pickup trigger was released (see Fig. 4). A virtual environment need not have glass cases as in the museums, as such users could freely access the artefacts and appreciate them from all angles, enhancing their access, and therefore the personal appreciation and interpretation of objects. We limited destructive actions for the purpose of showing respect towards cultural heritage. Users can freely navigate in the virtual environment by walking around in the real world, providing them with a direct mapping between their physical movements and their positions in the virtual environment [17]. This reduces the possibility of simulator sickness generally caused by teleportation and sudden directional change. VR user received visual and auditory cues when the AR user observed an artefact. 
AR users was provided with a cube with six faces with a side of $6 \mathrm{~cm}$, each with an image pattern that a cultural heritage object was augmented on (see Fig. 5). We designed the physical cube as an embodiment of the six artefacts as well as for their interactions. This followed the principle of embodied interaction [18] in that it allowed users to manipulate the cultural artefacts through the engaged interactions with the cube. By rotating the physical cube, the AR user could observe an object from different angles within the real world. Together with the artefact information, the object became an interface between VR and AR users as it created their shared experience. When an AR user looked at the augmented object, the same object was rotated triggering a sound effect within the virtual environment, providing visual and auditory cues to draw their attention towards the object. This necessarily promotes initial engagement between users with different devices. We consider $\mathrm{VR}$ and $\mathrm{AR}$ as being from different worlds, using different devices and therefore, the need for objects to be an interface connecting them. This is the value and contribution of our present research.

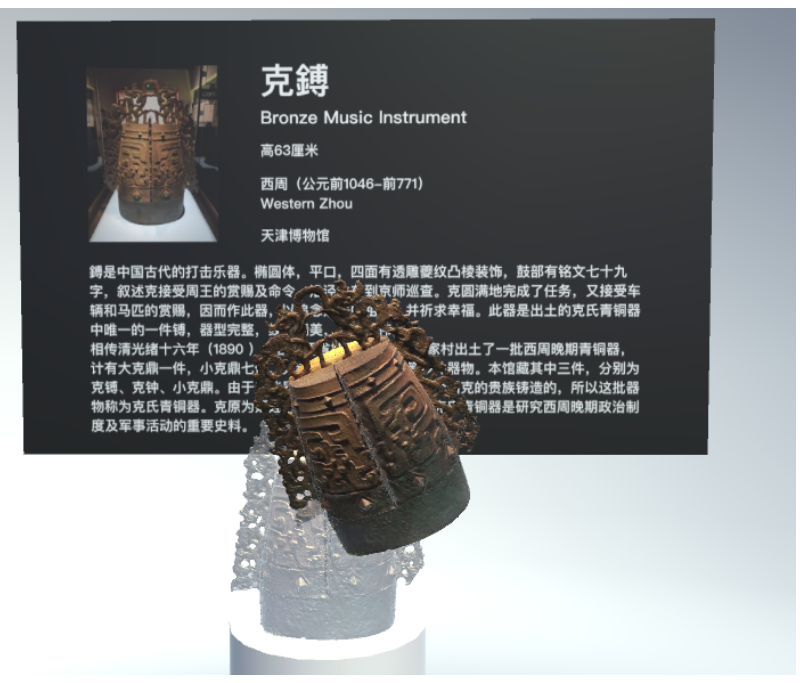

Fig. 4. The visual cue indicating that the object being picked up can be snapped back to its original location

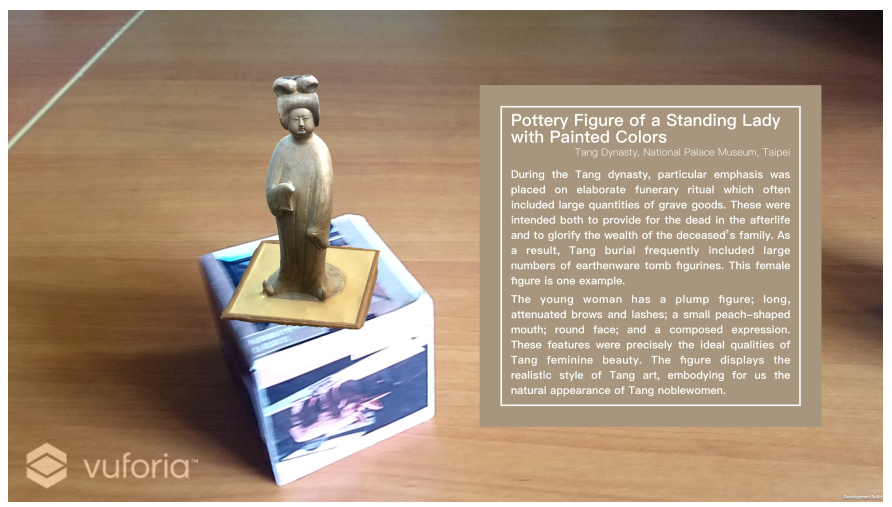

Fig. 5. The physical AR cube with augmented artefact model and information label displayed within the mobile phone's AR viewport

\section{B. User Study}

We conducted a user study investigating users' acceptance of the use of hybrid VR and AR for cultural heritage, as well as the social nature of multiple co-located user interaction. Each set of experiment involves a VR user and an AR user.

\section{1) Demographics Group}

In total, we involved 52 users (28 males, 24 females) as 26 pairs in the study. The demographics of users are given in Table II. Most users were aged between 18 and 34. A majority of them were Chinese, and most pairs of users knew each other.

\section{2) Study Environment}

The experiments took place at the NVIDIA Joint-Lab on Mixed Reality, an NVIDIA Technology Centre at the University of Nottingham's China campus. A $2.5 \mathrm{~m}$ x $2.5 \mathrm{~m}$ space was used, calibrated with the HTC Vive for freedom of movement.

TABLE II. DEMOGRAPHICS OF USERS

\begin{tabular}{cccc}
\hline Category & Item & Frequency & Percentage \\
\hline \multirow{2}{*}{ Gender } & Male & 28 & $53.85 \%$ \\
& Female & 24 & $46.15 \%$ \\
\hline Age & $18-24$ & 30 & $57.69 \%$ \\
& $25-34$ & 19 & $36.54 \%$ \\
& $35-44$ & 2 & $3.85 \%$ \\
& $45-54$ & 1 & $1.92 \%$ \\
\hline Chinese & Yes & 47 & $90.38 \%$ \\
& No & 5 & $9.62 \%$ \\
\hline Knew each & Yes & 20 & $76.92 \%$ \\
other & No & 6 & $23.08 \%$ \\
\hline
\end{tabular}

\section{Data Collection and Data Analytics}

\section{1) Data Collection}

The pre-experiment questionnaires had three sections: user demographics, including gender, age, profession; previous experience and familiarity with 3D gaming, VR and AR; and previous experience with museum visits, interests in cultural heritage, and knowledge of Chinese artefacts. After each experiment, users were asked to fill in a technology acceptance questionnaire, in which items were taken from the UTAUT questionnaire and adapted to fit within the context of our hybrid VR and AR research. Our experiment was designed to test our hypotheses (see Fig. 1). The key questions asked in the interview were related to their general feelings of the experience with the hybrid system, the knowledge they acquired when accessing heritage contents, their expectations on the technology use, and interaction limitations which failed their expectations. Specific questions were asked to further understand the observed user reactions and conversations during the experience, such as a specific movement or comments they made. Users were also invited to provide suggestions for future improvements. 


\section{2) Data Analysis}

The data collected from questionnaires were analysed and visualised using SmartPLS [19] to test the reliability of each construct, and to identify the correlations and regression patterns between constructs for statistical significance. Analysed results were compared with our initial hypotheses. Qualitative data from observation notes and interviews used thematic analysis to understand narratives and the thoughts of users.

\section{RESULTS}

\section{A. Pre-experiment Questionnaire}

Our pre-experiment questionnaire asked questions about users' prior experience with 3D gaming, VR, and AR. 63\% of our users had 3D gaming experience; $62 \%$ of the users had VR experience; and $42 \%$ of the users had AR experience. We found that users with 3D gaming experience are skilful at it. Users are less skilful with VR and AR overall (see Fig. 6). Our findings also showed that length of time users had with $3 \mathrm{D}$ games positively correlates with their perceived 3D gaming skills $(R=$ $0.85, p<0.05)$, which also relates positively with their skills with VR $(R=0.55, p<0.05)$ and $\mathrm{AR}(R=0.57, p<0.05)$.

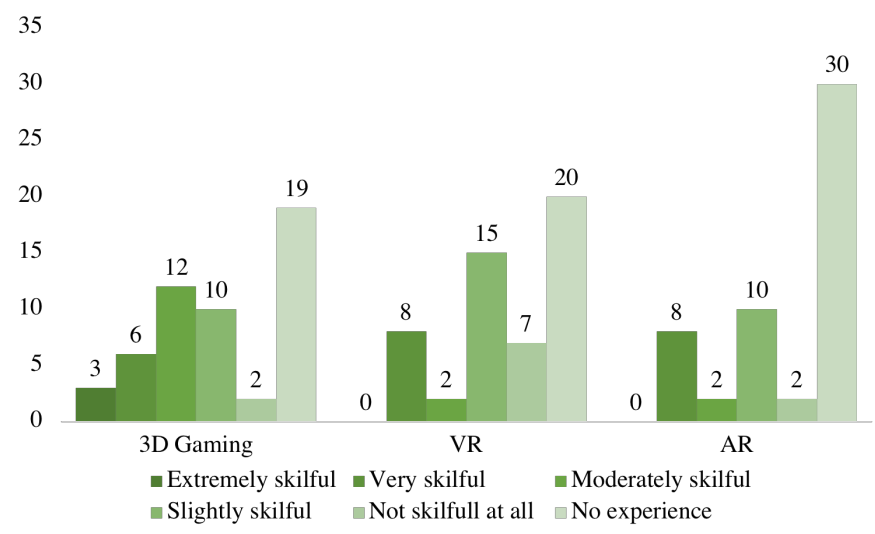

Fig. 6. Self-reported (perceived) skills in 3D gaming, VR, and AR

Although most 360 videos are not interactive and sometimes not considered as VR, they can provide an immersive experience. We therefore listed it as an option for users for claiming to have prior VR experience. Half of the VR users $(50.0 \%)$ reported to have watched 360 'VR' videos or movies; In our data, most VR users have played VR games (59.4\%), while few have experienced VR-based exhibits or educational apps $(28.1 \%)$. The devices they used were mostly HTC Vive (59.4\%) and Samsung Gear VR (53.1\%), followed by the Oculus Rift (21.9\%) and Google Cardboard (6.3\%). Most AR users used it for games (81.8\%) and maps (72.7\%). Some used AR for marketing campaigns (40.9\%) and as tour guide systems (18.2\%). In addition, $13 \%$ of all users responded that they have had VR or AR experience with other users. The examples they provided were playing Pokémon Go and watching VR movies together with their friends. None has had experience with hybrid VR and AR systems.
Knowledge of museums and cultural heritage were shown to be average in our users. $46.2 \%$ of users perceived that they were moderately knowledgeable, $48.1 \%$ of users rated slightly knowledgeable and $5.8 \%$ of users rated not knowledgeable at all. However, interest is there. When users saw interesting objects in museums, they tend to read the information label (73.1\%), take a picture (73.1\%), and engage in social activities, such as asking someone to join in for discussions (34.6\%). Users also send messages to friends or posts on social media (40.4\%). $34.6 \%$ of our participants reported that they would search for more information on the Internet. This implies that users are naturally inclined to acquire and share information. To our participants, the museum visiting experience was more than a learning process, it was also for social activities both inside and outside the boundaries of museums, which are perceived to be important aspects of their social life.

\section{B. Acceptance Questionnaire}

The acceptance questionnaire used in this study was adapted from the UTAUT model [11], using a 5-point Likert-type scale ranging from Strongly Disagree (1) to Strongly Agree (5). In order to validate the instruments and test the hypothesised relationships between social influence, performance expectancy, effort expectancy, and behavioural intention, we performed structural equation modelling (SEM), assessing both measurement model and structural model.

\section{1) Measurement Model Assessment}

Partial least squares path modelling (PLS-PM) was applied to generate the estimation of item loadings and path coefficients [20]. The results are shown in Table III. The correlations between the questionnaire items and the constructs are illustrated by factor loadings. All factor results of instruments applied in this study were greater than 0.72 , which exceeded the suggested factor loading value of 0.50 [21] and met a stricter threshold value of 0.70 [22]. With the factor loadings, the composite reliability (CR) and the average variance extracted (AVE) can be calculated with (1) and (2), where $\lambda$ is the factor loadings and $\delta$ is the measurement error, $\delta_{\mathrm{i}}=1-\lambda_{\mathrm{i}}^{2}$. The Cronbach's Alpha, CR and AVE are indicators of the construct reliability and validity. Cronbach's Alpha measures the internal consistency, that is, how closely related a set of items are as a group. Items used in different constructs were shown to be robust and reliable measures regarding the Cronbach's Alpha was greater than 0.70 in all cases. The composite reliabilities of the constructs ranged from 0.85 to 0.91 and the average variance extracted ranged from 0.58 to 0.75 , which exceed the recommended threshold values of 0.70 and 0.50 respectively [21]. Therefore, the constructs in the model have sufficient reliability and convergent validity.

$$
\begin{gathered}
\mathrm{CR}=\frac{\left(\sum_{i=1}^{n} \lambda_{i}\right)^{2}}{\left(\sum_{i=1}^{n} \lambda_{i}\right)^{2}+\left(\sum_{i=1}^{n} \delta_{i}\right)} \\
\mathrm{AVE}=\frac{\sum_{i=1}^{n} \lambda_{i}^{2}}{n}
\end{gathered}
$$


TABLE III.

RELIABILITY AND VALIDITY OF RESEARCH VARIABLES

\begin{tabular}{lccccc}
\hline & Indicator & $\begin{array}{c}\text { Factor } \\
\text { Loadings }\end{array}$ & $\begin{array}{c}\text { Cronbach's } \\
\text { Alpha }\end{array}$ & CR & AVE \\
\hline PE & PE1 & 0.87 & 0.84 & 0.89 & 0.68 \\
& PE2 & 0.82 & & & \\
& PE3 & 0.84 & & & \\
& PE4 & 0.76 & & & \\
EE & EE1 & 0.82 & 0.86 & 0.91 & 0.71 \\
& EE2 & 0.89 & & & \\
& EE3 & 0.85 & & & \\
& EE4 & 0.81 & & & \\
SI & SI1 & 0.72 & 0.76 & 0.85 & 0.58 \\
& SI2 & 0.78 & & & \\
& SI3 & 0.76 & & & \\
& SI4 & 0.78 & & & \\
BI & BI1 & 0.87 & 0.83 & 0.90 & 0.75 \\
& BI2 & 0.89 & & & \\
& BI3 & 0.84 & & &
\end{tabular}

\section{2) Structural Model Assessment}

PLS-PM does not assume a normally distributed data, which disqualifies the parametric tests for significance. Therefore, the bootstrapping procedure was applied to perform non-parametric tests to obtain the statistical significance of the path model coefficient [23]. The results showed that the model fits the study data as indicated by estimates, $R$-squared, and significance values (see Fig. 7 and Table IV.). All paths in the model are shown to be statistically significant $(p<0.05)$ and the model fits the overall data $\left(R^{2}=0.55\right)$. As a result, all four hypotheses were found to be supported.

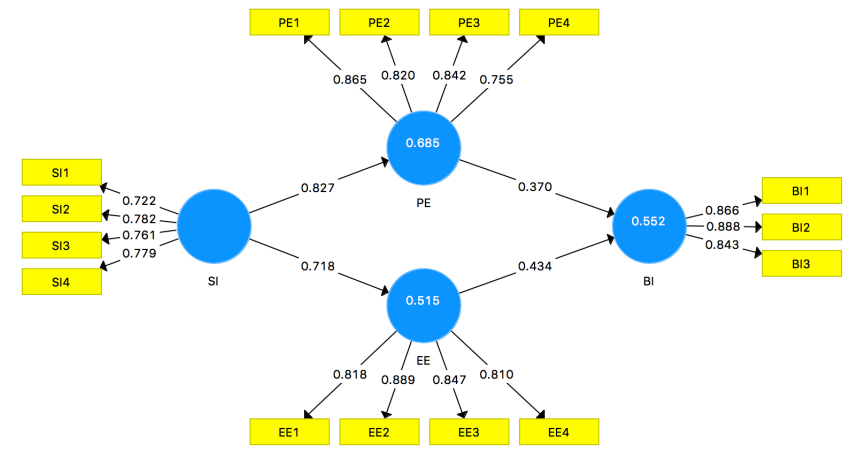

Fig. 7. Research model results

TABLE IV.

RESULTS OF HYPOTHESIS TESTING

\begin{tabular}{ccccc}
\hline Hypothesis & Estimates & $\boldsymbol{t}$-value & $\boldsymbol{p}$-value & Confirmed \\
\hline H1: SI -> PE & 0.83 & 12.32 & 0.00 & Yes \\
H2: SI -> EE & 0.72 & 7.43 & 0.00 & Yes \\
H3: PE -> BI & 0.37 & 2.60 & 0.01 & Yes \\
H4: EE -> BI & 0.43 & 3.53 & 0.00 & Yes \\
\hline
\end{tabular}

\section{Observations and Interview}

General feedback about the hybrid VR and AR experience was positive. VR users responded that the environment was immersive, and the objects looked real. The object-grab interaction was intuitive and helpful as it allowed them to observe objects from different angles, which is not possible in museums considering the risk of breaking the artefacts. Some also compared this interactive VR experience with their previous 360 video experience and responded that the interactions engaged them better and were fun to play with. AR users acknowledged the great quality of the models and reported that seeing the 3D models of artefacts augmented on top of the 2D images on their cube surfaces felt like the artefacts came alive. They also reported that holding the cube with digital artefacts is comparable to holding the objects in hand. The interaction with 2D images on the sides of the cube helped support the user mental model that the smartphone camera can transform the 2D image of a cultural artefact into an equivalent 3D model. The use of a physical cube of appropriate size provided users with physical embodiments of the artefacts [18] and gave users the impression that the cube embeds the artefacts and that the smartphone camera is the key to unlock them.

During the experiment, most interactions between the VR user and the AR user occurred around our virtual objects, which achieved our goal of object as interface. In most cases, VR users noticed the changes in the virtual environment, and asked "Are you looking at the Tri-coloured Camel (object \#5, see Table I.)?" when they saw an object rotating. Moreover, most of them walked towards the object and looked at it with their paired partner if they noticed the change. We have also found AR users prompting the VR user to engage with an object of interest together. Although the virtual environment was a simple room without any historical context, and AR users only had access to 3D models and information label of the objects, the objects they shared became the interface between them, connecting them and mediating their communications. We found that most discussions were initiated by users' observation of the appearance of the artefacts, such as their shape and colours. Users were seen to develop conversations through the sharing of their interpretations of the objects as well as their associated knowledge from literatures or from visiting museums. A user who first saw the 3D Bronze Mask (object \#2, see Table I.) initiated a discussion, explaining to his partner about the history behind the artefact because it reminded him of the Sanxingdui documentary film he had previously watched. Some related the artefacts with stories they have heard from their friends, as well as news they have read elsewhere. For example, a girl narrated a piece of news she read and said how she wished the Pottery Unicorn (object \#4, see Table I.), as a symbol of justice, could help punish the bad guy in the news. With the shared objects provided as a communication interface, users had generated interesting contents during the experience, both within and beyond the scope of the cultural heritage context we have provided in our experiment. This suggested that despite the different technology used and the limited information provided, the $3 \mathrm{D}$ objects themselves were mediating communications. 
Although the control methods were identical across our 26 pairs of users, some were creative with their interactions. Because the Figure of an Assistant to the Judge of Hell (object \#6, see Table I.) was a statue of 5 feet, we deliberately made it immovable in the virtual environment, which made it difficult for the VR user to observe its back. However, some VR users asked their AR partner to observe it, triggering a rotation so that they could see it from the back. This spontaneous cooperative interaction illustrated how users can become creative in taking advantage of the asymmetrical access to engage with the system and the other users. It also provided inspirations for our future design, incorporating asymmetrical access [9] to foster user interaction, engagement, and communication.

In another example, VR users switched the positions of artefacts in the virtual environment and put them back to the original positions before the experiment was completed. When being asked about the action, they reported that they initially explored the possibility of placing the object randomly within the environment but failed. However, they realised that the objects could switch places, i.e., pedestals, and being courteous, they placed the objects back at their original locations so that new users will not be confused. This demonstrated that users were willing to explore the affordances of the environment and that they could adapt to it quickly. More importantly, users took the virtual environment as a social environment, and that they were expecting others to see what they saw. Such observed behaviour should be supported and made used of in the future design of multiuser virtual environments if we intend to include a community for supporting, moderating and maintaining usergenerated content.

Social presence was also reported in our experiment. We observed that there were infrequent interactions between a pair of users who were strangers to each other, they reported that although they did not have the intention of approaching the other user, they had the sense that, through the cues given by the object, they were accompanied by another person during their experience. The awareness of another user through the object as an interface mitigated loneliness for them in a fully immersive environment.

\section{Limitations}

Our current design of the hybrid VR and AR system is not without limitations as it is preliminary and exploratory. Therefore, limitations and underestimation of the experience is expected. Here we report on the limitations of the environment, which will inform our future design of our pioneering system.

We observed that there were interactions which failed user expectations. Some VR users attempted to affect the AR user by making the artefact disappear or move when they picked up the object on their side, which is the virtual environment. During the interview, our users reported that it would have been more interesting if they could affect their partner's world via some interaction mechanisms. One of the advantages which users highlighted, for the reasons they liked VR and AR technologies were that these technologies can allow more dynamic interactions as compared to physical museum. The use of such devices is expected for future applications for cultural heritage. A user narrated that when he found that he could not move the Figure of an Assistant to the Judge of Hell (object \#6, see Table I.), his immediate thought was to work together with his partner to try to lift it up. These reflections supported the idea that the future design of hybrid VR and AR system should include more flexible affordances. Users have also suggested that games should be introduced to promote learning, such as categorising artefacts based on materials or sorting them according to historical, chronological sequence. Incorporating such game elements supports a playful environment, which corroborates the idea of gamification, empowering motivation, engagement, and loyalty [24]. We have also discovered that most users came to the conclusion that the interactions with objects and their partners contributed to their understanding and interpretation of cultural heritage. The social interaction within the environment encouraged paired users to observe more and read more, culminating in more knowledge gained from the experience and strengthening their memory.

\section{CONCLUSION}

This research explored the use of a hybrid VR and AR system in a multiuser cultural heritage application, and confirmed the proposed research model on acceptance. We demonstrated, through our analysis of our datasets from 52 participants in 26 pairs, that users' behavioural intention depends on performance expectancy and effort expectancy, which are positively affected by social influence. Users considered the technology we have developed helpful in giving access to cultural heritage objects. They have found that the interface was easy to use. The understanding of the social nature of users and developing technology in supporting it is fundamental to manage their expectations resulting in the achieving of higher behavioural intentions. Our study has confirmed that social influence is important, and should be taken as a significant factor in the future design of multiuser systems supporting different devices and interface features.

In addition, the social nature that users possess in their actual museum visiting experience can be transferred to the virtual environment - their interaction and communication were mediated by cultural artefacts. Many users took museum visiting as a social activity involving families and friends. Users also engaged in social activities outside the boundary of the museums, such as the sharing of their experience via social media. Our observations and interviews confirmed such a social nature and supported the idea that the virtual heritage objects could be an interface between their interaction and communication. Interactions around digital interfaces have been shown to be useful to promote new topic of discussion and foster communication [25]. Our study further showed that digital objects, together with the discussions and communication that users initiated themselves, assisted with user interpretations of the artefacts, facilitated by the virtual environment and the interactions afforded by the different devices. Furthermore, users perceived social presence within 
the virtual environment and felt a sense of immersion and accompaniment. They acknowledged the positive influence of their interactions with others on their experience and expected more interaction possibilities and closer connections with other users. Users have expressed that such a system should include game elements in the future design of hybrid VR and AR systems. Our findings also indicated a positive relationship between 3D gaming experience and skills in VR and AR, although the experiment showed that the control methods were intuitive enough for first time users to learn and master quickly. This may have explained their expectations for richer interactions and the presence of game elements.

The findings contributed to both the theoretical and methodological frameworks which will help guide the future design of multiuser digital systems for cultural heritage and 'museums outside the walls' facilitating the social nature of museum visits. However, the results should be interpreted carefully due to these observed limitations. First, the majority of users in our study participated with people they knew beforehand. The actual interaction, engagement, and communication between strangers will need to be studied. Second, the majority of our users were university students, aged between 18 and 35 . Therefore, the results may not be applicable for general museum visitors. However, this indicates an opportunity to attract younger visitors. We felt that a more comprehensive study is required to understand users of other age groups, such as family units with children. However, the younger users in this study are more likely to be open to new technologies and to have their own VR and AR devices in the future. The understanding of their acceptance and behaviour is nevertheless significant for future VR and AR system design in cultural heritage.

\section{ACKNOWLEDGEMENT}

This work was carried out at the NVIDIA Joint-Lab on Mixed Reality. The authors acknowledge the financial support from International Academy for the Marine Economy and Technology (IAMET), Ningbo Education Bureau, Ningbo Science and Technology Bureau, Zhejiang Provincial commonwealth grant, China's MOST and the University of Nottingham. This work is part of the International Doctoral Innovation Centre (IDIC) programme and partially supported by EPSRC grant no EP/L015463/1.

\section{REFERENCES}

[1] J. Forlizzi and K. Battarbee, "Understanding Experience in Interactive Systems," Conf. Des. Interact. Syst., pp. 261-270, 2004.

[2] E. Ch'ng, "Experiential Archaeology: Is Virtual Time Travel Possible?," J. Cult. Herit., vol. 20, no. 2009, pp. 458-470, 2009.

[3] F.-T. Leow, E. Ch'ng, T. Zhang, S. Cai, and S. See, “'In-The-Wild' Observation and Evaluation of a Chinese Heritage VR Environment with the HTC VIVE," in International Conference on Virtual Systems and Multimedia (VSMM), 31 Oct - 2 Nov, 2017.

[4] I. E. Sutherland, “The Ultimate Display," Invit. Lect.IFIP Congr., vol. 65, pp. 506-508, 1965.
[5] E. Ch'ng, R. Stone, and T. Arvanitis, "The Shotton River and Mesolithic Dwellings: Recreating the Past from Geo-Seismic Data Sources," 5th Int. Symp. Virtual Reality, Archaeol. Cult. Heritage, VAST, pp. 125-133, 2004.

[6] V. Gaffney, S. Fitch, E. Ramsey, R. Yorston, E. Ch'ng, E. Baldwin, R. Bates, C. Gaffney, C. Ruggles, T. Sparrow, A. McMillan, D. Cowley, S. Fraser, C. Murray, H. Murray, E. Hopla, and A. Howard, "Time and a Place: A Luni-solar 'Time-Reckoner' from 8th Millennium BC Scotland," Internet Archaeol., vol. 34, no. 34, 2013.

[7] M. Roussou, L. Pujol, K. Akrivi, i C. Angelik, P. Sara, and M. Vayanou, "The Museum as Digital Storyteller: Collaborative Participatory Creation of Interactive Digital Experiences," MW2015 Museums Web, p. 210, 2015.

[8] E. Ch'ng, "New Ways of Accessing Information Spaces using 3D Multitouch Tables," in Proceedings of the 2012 International Conference on Cyberworlds, Cyberworlds 2012, 2012, pp. 144-150.

[9] J. Gugenheimer, E. Stemasov, J. Frommel, and E. Rukzio, "ShareVR: Enabling Co-Located Experiences for Virtual Reality between HMD and Non-HMD Users," in CHI '17, 2017, pp. 4021-4033.

[10] F. D. Davis, "A Technology Acceptance Model for Empirically Testing New End-User Information Systems," 1985.

[11] V. Venkatesh, "User Acceptance of Information Technology: Toward a Unified View," MIS Qarterly, 2003.

[12] A. Katifori, S. Perry, M. Vayanou, L. Pujol, A. Chrysanthi, Y. Ioannidis, A. Chysanthi, V. Kourtis, and Y. Ioannidi, "Cultivating Mobile-mediated Social Interaction in the Museum: Towards Group-based Digital Storytelling Experiences," MW2016 Museums Web 2016, pp. 1-14, 2016.

[13] M. Carrozzino and M. Bergamasco, "Beyond Virtual Museums: Experiencing Immersive Virtual Reality in Real Museums," J. Cult. Herit., vol. 11, no. 4, pp. 452-458, 2010.

[14] P. Zhang, "Motivational Affordances: Reasons for ICT Design and Use," Commun. ACM, 2008.

[15] J. M. Holden and J. B. Overmier, "Choice Behavior under Differential Outcomes: Sample Stimulus Control versus Expectancy Control," Learn. Motiv., 2015.

[16] Vuforia, "SDK Download I Vuforia Developer Portal," developer.vuforia.com, $2018 . \quad$ [Online]. Available: developer.vuforia.com. [Accessed: 03-Sep-2018].

[17] Y.Li, P. Tennent, and S. Cobb, "Appropriate Control Methods for Mobile Virtual Exhibitions,” in VRTCH'18, 2018.

[18] P. Dourish, Where the Action Is: The Foundations of Embodied Interaction, vol. 36, no. 3. 2001

[19] C. M. Ringle, S. Wende, and A. Will, "SmartPLS 3.0," 2005. [Online]. Available: http://www.smartpls.com. [Accessed: 03-Sep-2018].

[20] J. F. J. Hair, G. T. M. Hult, C. Ringle, and M. Sarstedt, A Primer on Partial Least Squares Structural Equation Modeling (PLS-SEM). 2014.

[21] J. F. Hair, W. C. Black, B. J. Babin, R. E. Anderson, and R. L. Tatham, "Multivariate Data Analysis," Prentice Hall, 2010.

[22] C. Fornell and D. Larcker, "A Second Generation of Multivariate Analysis: Classification of Methods and Implications for Marketing Research," Review of marketing, vol. 87. pp. 407-450, 1987.

[23] A. C. Davison and D. V Hinkley, "Bootstrap Methods and Their Application," Technometrics, 1997.

[24] S. Deterding, D. Dixon, R. Khaled, and L. Nacke, "From Game Design Elements to Gamefulness: Defining Gamification," Proc. 15th Int. Acad. MindTrek Conf. Envisioning Futur. Media Environ. - MindTrek'11, 2011.

[25] C. Rocchi, D. Tomasini, O. Stock, and M. Zancanaro, "Fostering Conversation After the Museum Visit," Proc. Work. Conf. Adv. Vis. interfaces - AVI '08, p. 335, 2008. 